Original article

\title{
Tadpole co-occurrence in ponds: When do guilds and time matter?
}

\author{
Camila Both $^{\mathrm{a}, \mathrm{b}, *}$, Adriano S. Melo ${ }^{\mathrm{c}, \mathrm{d}}$, Sonia Zanini Cechin ${ }^{\mathrm{e}}$, Sandra M. Hartz ${ }^{\mathrm{c}}$ \\ a Programa de Pós-Graduação em Ecologia, Universidade Federal do Rio Grande do Sul, CP 15007, Porto Alegre, RS CEP 91501-970, Brazil

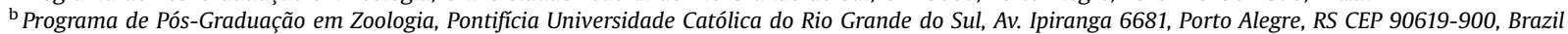 \\ ${ }^{c}$ Dep. Ecologia, Universidade Federal do Rio Grande do Sul, CP 15007, Porto Alegre, RS CEP 91501-970, Brazil \\ d Dep. Ecologia, Instituto de Ciências Biológicas, Universidade Federal de Goiás, CP 131, Goiânia, GO CEP 74001-970, Brazil \\ ${ }^{\text {e }}$ Dep. Biologia, Universidade Federal de Santa Maria, Av. Roraima, 1000, Cidade Universitária, Santa Maria, RS CEP 97105900, Brazil
}

\section{A R T I C L E I N F O}

\section{Article history:}

Received 21 May 2010

Accepted 9 January 2011

Available online 5 February 2011

\section{Keywords:}

Co-occurrence

Anuran larvae

Segregation

Nektonics

Benthics

\begin{abstract}
A B S T R A C T
An extensive meta-analysis study suggested that co-occurrence in communities composed mostly of ectotherm species would not be segregated in space. However, there is some evidence of segregated occurrence for ectotherms when guilds were considered in the analysis. Therefore the apparent randomness found in co-occurrence analyses may be a consequence of the pooling of heterogeneous groups. We tested the following hypotheses for tadpole pond communities: i) an analysis including all species will indicate random co-occurrence, ii) co-occurrence will differ between seasons, and iii) analysis of co-occurrence within guilds will reveal a segregated pattern. We sampled tadpoles in Caçapava do Sul, southern Brazil, in two seasons (spring, summer). Species co-occurrence patterns were analyzed using the C-score index and three null models. We collected 10,852 tadpoles of 21 species, which belonged to four guilds: benthics, nektonics, suspension-raspers, and suspension-filterers. The last two guilds contained only a single species each, and therefore the analyses were restricted to the benthic and nektonic guilds. We obtained contrasting results depending on the null model. We used results only from non-degenerate simulated matrices. The co-occurrence of all species analyzed together was random in both seasons. Benthic tadpoles showed a tendency to segregated co-occurrence in spring, and random co-occurrence in summer. Nektonic tadpoles showed random co-occurrence for the total and the spring matrices, and segregated co-occurrence in summer. Our results indicate that the strength of negative co-occurrence may depend on season and guild. We conclude that apparent random cooccurrences of ectotherm communities may actually result in a segregated structure when restricted to a single guild, which is in concordance with other studies where guilds were considered, and supports the hypothesis that an apparent lack of negative associations might be related to the study of heterogeneous groups.
\end{abstract}

() 2011 Elsevier Masson SAS. All rights reserved.

\section{Introduction}

To understand the relevance of assembly rules for community structure is one of the major challenges for ecologists. Why do some species never, and other species always occur together? Are competitive interactions patterning communities? A landmark in this debate was Diamond's (1975) proposal that competition structures the distributions of birds on the islands of the Bismarck Archipelago, and the resulting controversy regarding how to detect competition from distributional data (Connor and Simberloff,

\footnotetext{
* Corresponding author. Programa de Pós-Graduação em Zoologia, Pontifícia Universidade Católica do Rio Grande do Sul, Av. Ipiranga 6681, Porto Alegre, RS CEP 90619-900, Brazil. Fax: +55 5133203903.

E-mail address: camilaboth@gmail.com (C. Both).
}

1979). Thirty years after Diamond's work, many developments in theoretical frameworks and analytical tools have appeared, although these still need further investigation of their general applicability (Gotelli and McCabe, 2002).

In a meta-analysis of 96 presence-absence matrices, Gotelli and McCabe (2002) evaluated the co-occurrence patterns of different taxonomic groups, and found evidence of structure in most communities, mainly within homeotherms. They did not find indications of structured communities for fishes, amphibians, reptiles, and most invertebrates, except for ant assemblages. Based on this difference between homeotherms and ectotherms, it was suggested that the co-occurrence pattern of animal communities is ordered in a "continuum" (Gotelli and McCabe, 2002; Gotelli and Rohde, 2002). In this way, small animals, with less mobility and with small populations would be less subject to competitive pressures, and therefore would show co-occurrence patterns similar to 
those expected by chance. In contrast, large and/or highly mobile animals with large populations would tend to show segregated or checkerboard distributions (Gotelli and Rohde, 2002). It should be noted, however, that negative associations among species pairs may result from groups that use different habitats (Diamond and Gilpin, 1982). Species may not co-occur because they exploit different habitats (Sfenthourakis et al., 2005). Additionally, analyses including assemblages that are heterogeneous regarding resource use would dilute competitive effects and tend to show a lack of competition, when it in fact exists (Diamond and Gilpin, 1982). This last confounding factor is particularly relevant, because previous analyses of co-occurrences usually included all species in the assemblage and not only those for which a plausible competitive hypothesis could be suggested.

The guild approach is traditionally used in community ecology, and is based on the idea that communities are built from groups of species that share ecological and/or phylogenetic similarities (Blondel, 2003). It is not expected that all species will show competitive interactions, but only those that use resources in a similar way (Simberloff and Dayan, 1991). Therefore, the characterization and designation of an ecological guild constitute a fundamental step for the competitive interaction analysis, although the two processes are carried out independently (Gotelli and Entsminger, 2007). In fact, recent studies that evaluated cooccurrence within guilds found evidence of structure in some ectotherm communities. For example, Sanderson (2004) evaluated the confamilial co-occurrence of amphibians, and found checkerboard patterns for some cases that had been considered random in a previous analysis (Hofer et al., 1999). Hofer et al. (2004) found evidence of structure for lizards in a null-model analysis in which species traits were taken into account. Luiselli (2006) reviewed snake community studies and found evidence of competition for habitat depending on the snake guild and the geographical region. Luiselli (2008) showed that competition should be important to freshwater turtle communities. Heino (2009) studied stream macroinvertebrates and found non-random patterns of co-occurrence within guilds, and Dilling et al. (2007) reported segregation for some insect guilds associated with the hemlock Tsuga canadensis. Jenkins (2006) studied co-occurrence of zooplankton communities and found evidence of segregated patterns in a nullmodel analysis in which species was proportional to area. All these studies based on ectotherm communities challenge the continuum hypothesis, even though random co-occurrence has been reported for other ectotherm guilds (e.g., Krüger et al., 2010).

Pond communities provide a good opportunity to study assembly rules, because they have easily recognizable limits, similarly to islands, where assembly rules have historically been studied (Chase and Leibold, 2003). The presence of tadpoles in a pond relies, in the first instance, on the site that adults choose for egg deposition. The type of habitat selected strongly influences the development of most species (Alford, 1999; Ryan and Winne, 2001). Larvae that develop in permanent habitats are less exposed to hydric stress, but are generally exposed to a wide variety of potential predators and competitors (Alford, 1999). Thus, different traits are expected to be required to occupy ponds in the different positions along the permanence gradient. Changes in composition of species across gradients of pond permanence have been documented (Richter-Boix and Llorente, 2007; Snodgrass et al., 2000; Welborn et al., 1996).

The tadpole community structure in ponds has been attributed mostly to predation, competition, and degree of permanence of the pond. Heyer et al. (1975) suggested that habitat permanency would determine species composition in ephemeral ponds, whereas competition and other biotic interactions would have major roles in more-permanent habitats. Wilbur (1987) manipulated these three factors experimentally, and concluded that the importance of each factor depends on the species studied and on the habitat, in agreement with Heyer et al. (1975). Additionally, the results of Wilbur (1987) indicated that competition is a patterning pressure in small and short-permanence habitats, and that predators attenuate competition in more-permanent ponds.

Subsequent experimental and observational studies that assessed segregation patterns of tadpoles attributed different values to competitive interactions. Laboratory and mesocosm experiments indicated that competition has an important role in structuring tadpole communities (e.g., Morin, 1987; Morin and Johnson, 1988; Parris and Semlitsch, 1998). On the other hand, observational studies tended to assign less importance to competitive interactions (e.g., Eterovick and Barros, 2003; RossaFeres and Jim, 1996; Wild, 1996). In fact, some authors have questioned the prevalence of competition for communities in natural conditions (Chase and Leibold, 2003), and hypothesized that under such conditions, heterogeneity and predation would attenuate and/ or prevent competition (Lawler and Morin, 1993; Morin, 1983).

Amphibian breeding activities are strongly related to timestructured variables (see Both et al., 2008; Canavero and Arim, 2009; Prado et al., 2005; Toft, 1985). Studies that assessed the temporal occurrence of amphibians, unsurprisingly, found segregated co-occurrence patterns (e.g., Canavero et al., 2009; Sanchez et al., 2009). This seasonal component of amphibian communities could prevent both adult and larval species co-occurrence (Glasser, 1989), and should be taken into account even in spatial studies.

We investigated the co-occurrence of tadpoles in pond assemblages considering all-species records, and also restricting analyses to within guilds and seasons. We hypothesized that: i) in the search for structure using all species, the co-occurrence pattern would be random as a result of the dilution effect; ii) pond conditions vary greatly in time, and thus co-occurrence patterns may differ between seasons; and iii) within guilds, the co-occurrence models would reveal a segregated pattern.

\section{Materials and methods}

\subsection{Study area and sampling}

The study area comprised rural sites in the municipality of Caçapava do Sul, Rio Grande do Sul, southern Brazil (between $30^{\circ} 57^{\prime}$ and $31^{\circ} 03^{\prime} \mathrm{S}, 53^{\circ} 25^{\prime}$ and $53^{\circ} 89^{\prime} \mathrm{W}$ ), located in the Pampa biome (IBGE, 2004). The landscape is composed by natural grasslands and pastures, with small forest patches on hills and in valleys. The grasslands are mostly used for cattle and sheep grazing. The climate is classified as Temperate Humid, with an annual mean temperature of $16.8^{\circ} \mathrm{C}$ and annual precipitation of $1588 \mathrm{~mm}$ (Maluf, 2000).

We sampled tadpoles in 38 natural ponds of different sizes and degrees of permanence. Each pond was sampled twice: in November 2007 and January 2008 (respectively austral spring and summer). All ponds were sampled within seven consecutive days in spring, and five days in summer. We measured the area and depth of each pond in each collection event. For depth, we took the mean of three to six measurements obtained in each pond, depending on its size. A detailed description of pond descriptors is available in Both et al. (in press). Of the 38 ponds with water in the spring sampling, only 21 still contained water in the following summer sampling event. The volume reduction or drying of ponds observed in summer months is related to the increase of evaporation rates in subtropical regions (Both et al., 2009). Tadpoles were collected with a dip net $(0.4 \times 0.3 \mathrm{~m} ; 0.5 \mathrm{~mm}$ mesh $)$, which was swept all around the pond once only. The collected tadpoles are housed in the 
herpetological collection of the Universidade Federal de Santa Maria (ZUFSM), Brazil.

\subsection{Presence/absence matrices}

First, we compiled two presence/absence matrices: i) a spring occurrence matrix, containing the species recorded in 38 ponds and ii) a summer occurrence matrix, including the 15 species found in 21 ponds that retained water. In order to test the hypothesis that competitive interactions would be best reflected in intra-guild groups, each of the two matrices was divided according to guilds. Criteria used for guild designation followed Altig and Johnston (1989) and are detailed in Both et al. (in press).

\subsection{Co-occurrence patterns}

We tested if the co-occurrence pattern observed in each matrix differed from that expected by chance, comparing it with 30,000 matrices randomized according to a null model. We used the C-score index of co-occurrence (Stone and Roberts, 1990), which measures the average number of checkerboard units (CU) between all pairs of species (Gotelli and Entsminger, 2007). In a competitively structured community or one in which species are segregated according to habitat, the observed C-score should be significantly higher than scores expected by chance according to a null model.

The choice of the null-model algorithm is a crucial step, where biological and statistical restrictions should be carefully taken into account. We built the null models based on three different algorithms. In the first null model, we fixed the total number of species occurrences and the species richness in each site. This is a traditional although very conservative null model (Gotelli, 2000; Gotelli and Graves, 1996). This model maintains the observed rarity or evenness of the original matrix. Similarly, this model maintains the pattern of rich and poor sites in the randomized matrices. Fixing total species occurrences and species richness at each site results in a very conservative null model because usually few combinations of simulated matrices can be produced (Gotelli, 2000). As an alternative null model, we fixed species occurrences, but weighted species richness in sites by their mean depths. We chose mean pond depth to weight models based on the results of Both et al. (in press), which showed that depth was the best variable that explained tadpole richness and guild composition of the present data. This fixed-weighted model is less conservative and takes into account the importance of the environmental descriptor, in addition to competition, in structuring the community (Heino, 2009; Jenkins, 2006). This procedure, however, can produce degenerated matrices, where some sites contain no species, which in turn may increase Type I error (Connor and Simberloff, 1979). One can argue that degenerated matrices are not too artificial because ponds can be naturally "degenerated", i.e., we can find filled ponds with no tadpoles. Taking these considerations into account, we built a third null model fixing species occurrences, weighting sites by mean depth, but excluding degenerated matrices. The null matrices were generated by sequential swapping (Gotelli and Entsminger, 2003, 2007). The analyses were carried out using EcoSim 7.72 software (Gotelli and Entsminger, 2007).

\section{Results}

We collected 10,852 tadpoles of 21 species, belonging to five families: Cycloramphidae (1), Hylidae (8), Leiuperidae (5), Leptodactylidae (6), and Microhylidae (1). The 21 species were initially assigned to four ecomorphological guilds: benthics, nektonics, suspension-raspers, and suspension-filterers. Two of the guilds were composed of a single species each. Phyllomedusa iheringii is a suspension-rasper tadpole, and Elachistocleis bicolor is a suspension-filterer. Both species were included only in the all-species analyses. The species list and guild designations are presented in Table 1.

The co-occurrence of all species analyzed together was random in spring $(P=0.673)$ and in summer $(P=0.512)$ in the fixed-fixed null model (Table 2). However, species co-occurrences were nonrandom in both seasons when using the fixed-weighted model which included degenerated matrices $(P=0.032$, spring; $P=0.033$, summer). In the fixed-weighted model discarding degenerated matrices, all-species co-occurrence was random in spring $(P=0.140)$ and tended to be non-random in summer $(P=0.064)$.

The co-occurrence for benthic tadpoles in spring also presented a low probability of randomness $(P=0.058)$, although it was not different from that expected by chance in summer $(P=0.864)$ in the fixed-fixed model. In the fixed-weighted model including degenerated matrices, benthic tadpoles also showed a segregated occurrence in spring $(P<0.001)$, and a random pattern in summer $(P=0.158)$. In the fixed-weighted model excluding degenerated matrices, benthic tadpoles showed a random co-occurrence in summer. It was not possible to obtain enough non-degenerated null matrices based on the benthic occurrence matrix in spring.

Nektonic tadpoles showed a random co-occurrence in spring $(P=0.404)$, and only a weak evidence of segregated co-occurrence in summer $(P=0.087)$ (Table 2$)$ in the fixed-fixed model. In the fixed-weighted model, the co-occurrence of nektonics was nonrandom for the spring and summer matrices $(P<0.001$ for both cases). In the fixed-weighted model without degenerated matrices, nektonics showed a segregated pattern $(P=0.002)$. It was not possible to build enough non-degenerated null matrices for the nektonic occurrence matrix in spring.

\section{Discussion}

Tadpole co-occurrence in these ponds showed contrasting patterns depending on the null model used. The results obtained based on the fixed-fixed and fixed-weighted excluding degenerated matrices models were mostly congruent. They tended to indicate that random co-occurrence patterns prevail when all species are analyzed together (Table 2). However, it was not possible to generate the null universe without degenerated

Table 1

Species list and guild designations of the 21 tadpole species collected in 38 ponds, in November 2007 and January 2008, at Caçapava do Sul, Brazil.

\begin{tabular}{llc}
\hline Species & Guild & Frequency \\
\hline Limnomedusa macroglossa & Benthic & 3 \\
Dendropsophus minutus & Nektonic & 16 \\
Hypsiboas albopunctatus & Benthic & 4 \\
Hypsiboas pulchellus & Benthic & 10 \\
Phyllomedusa iheringii & Suspension-rasper & 5 \\
Pseudis minuta & Nektonic & 7 \\
Scinax fuscovarius & Nektonic & 12 \\
Scinax granulatus & Nektonic & 11 \\
Scinax nasicus & Nektonic & 10 \\
Physalaemus biligonigerus & Benthic & 12 \\
Physalaemus cuvieri & Benthic & 11 \\
Physalaemus gracilis & Benthic & 23 \\
Physalaemus riograndensis & Benthic & 4 \\
Pseudopaludicola falcipes & Benthic & 7 \\
Leptodactylus chaquensis & Benthic & 2 \\
Leptodactylus fuscus & Benthic & 1 \\
Leptodactylus gracilis & Benthic & 3 \\
Leptodactylus latinasus & Benthic & 3 \\
Leptodactylus latrans & Benthic & 5 \\
Leptodactylus mystacinus & Benthic & 2 \\
Elachistocleis bicolor & Suspension-filterer & 15 \\
\hline
\end{tabular}


Table 2

Values of observed C-score and mean of C-scores obtained in 30,000 null simulations. Models fixed-weighted I, include degenerated matrices and in the fixedweighted II they were not permitted. Models in which the null hypothesis was rejected are indicated by $\left({ }^{*}\right)$ when the $P$-value was less than $0.05\left(^{* *}\right)$ when $P<0.01$ and $\left({ }^{* *}\right)$ when $P<0.001$.

\begin{tabular}{|c|c|c|c|c|c|}
\hline Species/guild & Season & $\begin{array}{l}\text { C-score } \\
\text { (obs) }\end{array}$ & Model & $\begin{array}{l}\text { C-score } \\
(\operatorname{sim})\end{array}$ & $P($ obs $>\operatorname{sim})$ \\
\hline \multirow[t]{6}{*}{ All species } & \multirow[t]{3}{*}{ Spring } & \multirow[t]{3}{*}{19.9} & Fixed-fixed & 20.08 & 0.673 \\
\hline & & & Fixed-weighted I & 17.54 & $0.032^{*}$ \\
\hline & & & Fixed-weighted II & 18.63 & 0.140 \\
\hline & \multirow[t]{3}{*}{ Summer } & \multirow[t]{3}{*}{8.51} & Fixed-fixed & 8.53 & 0.512 \\
\hline & & & Fixed-weighted I & 7.30 & $0.033^{*}$ \\
\hline & & & Fixed-weighted II & 7.57 & 0.064 \\
\hline \multirow[t]{5}{*}{ Benthics } & \multirow[t]{2}{*}{ Spring } & \multirow[t]{2}{*}{16.67} & Fixed-fixed & 14.79 & 0.058 \\
\hline & & & $\begin{array}{l}\text { Fixed-weighted I } \\
\text { Fixed-weighted II }\end{array}$ & 11.50 & $<0.001^{* * *}$ \\
\hline & \multirow[t]{3}{*}{ Summer } & \multirow[t]{3}{*}{4.18} & Fixed-fixed & 4.54 & 0.864 \\
\hline & & & Fixed-weighted I & 3.30 & 0.158 \\
\hline & & & Fixed-weighted II & 4.28 & 0.569 \\
\hline \multirow[t]{5}{*}{ Nektonics } & \multirow[t]{2}{*}{ Spring } & \multirow[t]{2}{*}{32.9} & Fixed-fixed & 32.76 & 0.404 \\
\hline & & & $\begin{array}{l}\text { Fixed-weighted I } \\
\text { Fixed-weighted II }\end{array}$ & 18.36 & $<0.001^{* * *}$ \\
\hline & \multirow[t]{3}{*}{ Summer } & \multirow[t]{3}{*}{16.3} & Fixed-fixed & 15.67 & 0.087 \\
\hline & & & Fixed-weighted I & 9.79 & $<0.001^{* * * *}$ \\
\hline & & & Fixed-weighted II & 13.42 & $0.002^{* *}$ \\
\hline
\end{tabular}

matrices for the benthic and nektonic matrices in spring. This was due to the presence of a proportionally large number of rare species and/or sites with only one species, i.e., a large number of zeros.

The fixed-weighted model with degenerated matrices indicated that five of the six matrices were non-random and showed low probabilities. Also, all probabilities were notably low in this model when compared with the other two models, which either prevented or discarded degenerated matrices. Based on the fixedweighted model with degenerated matrices, we would conclude that tadpole communities are segregated independently of the guild and the season. The effect of degenerated matrices in reducing probabilities was first noted by Connor and Simberloff (1979). Gotelli (2000) tested this effect and found that for most matrices it was less severe than the effect of the type of null model used. In this study, the degenerated effect was strong and probably due to the large proportion of zero values in the matrices. Accordingly, in the remaining discussion we will focus on the results from the other two models.

The results produced by the fixed-fixed model for both seasons supported our first hypothesis of lack of a segregation pattern when all species are analyzed together. Using the fixed-weighted nondegenerated model this hypothesis was also supported, although a weak evidence for segregation was observed in summer season. In the case of the all-species analysis, non-competitive species pairs should dilute the effects of negative associations among interacting species. The comparison restricted to species within guilds reinforced the suggestion of co-occurrence analysis for subsets of potentially interacting species (see Diamond and Gilpin, 1982; Gotelli and McCabe, 2002; Simberloff and Dayan, 1991). A guild approach reduces the variability and makes co-occurrence analysis more realistic because it considers species similarity (Diamond and Gilpin, 1982; Kelt and Brown, 1999) and evaluates associations within the habitat shared by species (Gotelli and Graves, 1996). This makes the results easier to interpret. On the other hand, in an analysis including species from all guilds, segregated patterns could appear based on the habitat checkerboard. This is a plausible hypothesis for the segregated co-occurrence pattern found for all species in the fixed-weighted non-degenerated model. For instance, $P$. iheringii, a suspension-rasper, is associated with deep ponds (Both et al., in press), and benthic species of Leptodactylus are associated with ephemeral ponds. Combining these species in a single matrix would result in a checkerboard distribution, although it would not be a consequence of competition.

Our second hypothesis predicted that co-occurrence patterns for each guild would differ over time, as previous studies have shown distinct amphibian breeding seasonality in subtropical regions (Both et al., 2008; Canavero et al., 2008; Sanchez et al., 2009). Of the 21 species found, 18 occurred in spring and 15 in summer, showing that some species pairs did not co-occur. Since tadpole guilds are intrinsically linked with the water column and/or their swimming abilities (Altig and Johnston, 1989), environmental changes in ponds that occur across seasons constitute a resource change for tadpoles from each guild. As expected, co-occurrence varied between the two seasons, but the specific pattern of cooccurrence was dependent on guilds.

The nektonic tadpoles showed a random distribution in spring, but presented a segregated pattern in summer based on the fixedweighted non-degenerated model. The fixed-fixed model did not reject the null hypothesis, but showed a tendency of segregation given by the low probability of randomness $(P=0.087)$. The ample availability of deep ponds in spring may prevent competition among nektonics. Species could share the plentiful resources and habitat represented by deep ponds. Conversely, the reduction in volume or even complete drying of ponds in summer may restrict occupancy to a few suitable sites, and thus competition may prevail. Instead, the benthic tadpoles tended to show a segregated distribution in spring, and a random one in summer. Shallow ponds should be scarce in spring, and benthic species would compete for ephemeral ponds or the margins of deep ponds. As the volume of ponds decreases in summer, the plentiful availability of shallow sites prevents competition among species. It should be noted that the preference for shallow ponds of benthics in this study is probably related to the nature of the species belonging to this guild, which were mostly from the families Leptodactylidae and Leiuperidae.

The importance of depth in modulating tadpole interactions has been documented in previous field studies. Eterovick and Fernandes (2001) analyzed the microhabitat use of tadpoles in streams and found that the position in the water column and depth, together with time of occurrence, were the best variables to distinguish microhabitat use. Species segregation in the water column was suggested by Rossa-Feres and Jim (1996), and Both et al. (in press) reported guild replacement along gradients of depth and permanence of water.

Welborn et al. (1996) suggested that the gradient of pond permanence represents a stress gradient for tadpoles. Deep ponds in spring and shallow ones in summer would represent stress for, respectively, benthic and nektonic species. It has been suggested that under stress conditions, co-occurrence would be positive or random because competition would be ameliorated (Bertness and Callaway, 1994). Our analyses, however, indicated potential segregated occurrences during stress conditions. Similarly to our results, evidence of segregated occurrences under stress conditions was found for sand-dune plant communities (Maltez-Mouro et al., 2010), soil arthropods (Pitzalis et al., 2010), and Mediterranean tadpole communities (Richter-Boix et al., 2007b).

Direct competition among tadpoles is not the only explanation for the observed patterns. Segregation among tadpoles that occupy small and ephemeral ponds may be the result of the choice of breeding sites by adults. There is experimental evidence that species typical of temporary ponds are usually poor competitors in permanent ponds (Richter-Boix et al., 2007a). Other studies showed that adults of some species choose breeding sites taking into account the presence of predators and competitors, in addition to the availability of oviposition sites (Resetaritis and Wilbur, 1991), 
and that the order of occupancy should influence the outcome of competitive interactions (Lawler and Morin, 1993). Therefore, the effects of one species on others would not be solely related to resource depletion and its consequences for growth and survival rates, as observed in classical competition experiments (e.g., Tilman et al., 1981). Instead, the observed segregation could be a result of interference (inhibition) mediated by priority colonizer effects.

Historical processes or phylogeny are currently employed to explain segregated distribution patterns, mainly in regional-scale studies (Bowers and Brown, 1982). On this scale, allopatric speciation can generate checkerboard patterns for some species pairs. However, phylogeny could explain segregation even at small scales (Taylor and Gotelli, 1994). The relationship between guild and phylogeny was not tested for tadpoles, and deserves future investigation (McDiarmid and Altig, 1999), as well as the role of phylogeny in producing segregated patterns. On the other hand, competitive interactions, history, and phylogeny are not mutually exclusive, and the checkerboard patterns could be a result of their interaction (Cornell and Lawton, 1992).

We found a segregated structure for pond tadpole communities, contrasting with the continuum hypothesis (Gotelli and McCabe, 2002; Gotelli and Rohde, 2002). However, these patterns were detectable only when co-occurrence was analyzed within each guild, the same situation in which evidence of non-random patterns has been observed for other ectotherms such as coral reef fishes (Medeiros et al., 2010) and stream and arboreal macroinvertebrates (Dilling et al., 2007; Heino, 2009). These results support the hypothesis that the lack of negative associations might be related to the study of heterogeneous groups, and that nonrandomness is not a general pattern for ectotherms. Co-occurrence for each guild also differed between seasons, indicating that the strength of interactions may vary over time, and may occur at different time periods for different groups of species.

\section{Acknowledgments}

We are grateful to B. Madalozzo, G. Soares, I. Kaefer, and T. Dalcin who collaborated in field and/or laboratory activities, and to A. Kwet and T.G. Santos for valuable help in tadpole identification. We also thank A. Kindel, D.C. Rossa-Feres, and T. Grant for suggestions on an earlier version of the manuscript, and T.G. Santos for a critical reading of this version. We thank the editor and two anonymous reviewers whose suggestions improved the manuscript. Janet W. Reid revised the English text. ICMBIO granted a collection permit for this study (Process 11689-1). CB was supported by a CAPES fellowship. ASM received a research fellowship (302482/2008-3) and grant (476304/2007-5) from the Conselho Nacional de Desenvolvimento Científico e Tecnológico (CNPq).SMH received a research fellowship (304036/2007-2) from CNPq.

\section{References}

Alford, R.A., 1999. Ecology: resource use, competition and predation. In: McDiarmid, R., Altig, R. (Eds.), Tadpoles: the Biology of Anuran Larvae. The University of Chicago Press, Chicago/London, pp. 240-278.

Altig, R., Johnston, G.F., 1989. Guilds of anuran larvae: relationships among developmental modes, morphologies, and habitats. Herpetol. Monogr. 3, 81-109.

Bertness, M., Callaway, R.M., 1994. Positive interactions in communities. Trends Ecol. Evol. 9, 191-193.

Blondel, J., 2003. Guilds or functional groups: does it matter? Oikos 100, 223-231.

Both, C., Kaefer, I.L., Santos, T.G., Cechin, S.Z., 2008. An austral anuran assemblage in the Neotropics: seasonal occurrence correlated with photoperiod. J. Nat. Hist. 42, 205-222.

Both, C., Solé, M., Santos, T.G., Cechin, S.Z., 2009. The role of spatial and temporal descriptors for neotropical tadpole communities in southern Brazil. Hydrobiologia $624,125-138$.

Both, C., Cechin, S.Z., Melo, A.S., Hartz, S. What controls tadpole richness and guild composition in ponds in subtropical grasslands. Aust. Ecol. (Article first published online: 28 SEP 2010), in press, doi:10.1111/j.1442-9993.2010.02183.x.
Bowers, M.A., Brown, J.H., 1982. Body size and coexistence in desert rodents: chance or community structure. Ecology 63, 391-400.

Canavero, A., Arim, M., 2009. Clues supporting photoperiod as the main determinant of seasonal variation in amphibian activity. J. Nat. Hist. 43, 45-48.

Canavero, A., Arim, M., Naya, D.E., Camargo, A., Rosa, I., Maneyro, R., 2008. Calling activity patterns in an anuran assemblage: the role of seasonal trends and weather determinants. North-West. J. Zool. 4, 29-41.

Canavero, A., Arim, M., Brazeiro, A., 2009. Geographic variations of seasonality and coexistence in communities: the role of diversity and climate. Aust. Ecol. 34, 741-750.

Chase, J.M., Leibold, M.A., 2003. Ecological Niches: Linking Classical and Contemporary Approaches. The University of Chicago Press, Chigago/London.

Connor, E.F., Simberloff, D., 1979. The assembly of species communities: chance or competition? Ecology 60, 1132-1140.

Cornell, H.V., Lawton, J.H., 1992. Species interactions, local and regional processes, and limits to the richness of ecological communities: a theoretical perspective. J. Anim. Ecol. 61, 1-12.

Diamond, J.M., 1975. Assembly of species communities. In: Cody, M.L. Diamond, J.M. (Eds.), Ecology and Evolution of Communities. Harvard University Press, Cambridge, Massachusetts, pp. 342-444.

Diamond, J.M., Gilpin, M.E., 1982. Examination of the "null" model of Connor and Simberloff for species co-occurrences on islands. Oecologia 52, 64-74.

Dilling, C., Lambdin, P., Grant, J., Buck, L., 2007. Insect guild structure associated with eastern helmok in the southern Appalachians. Environ. Entomol. 36, 1408-1414.

Eterovick, P.C., Barros, I.S., 2003. Niche occupancy in south-eastern Brazilian tadpole communities in montane-meadow streams. J. Trop. Ecol. 19, 439-448.

Eterovick, P.C., Fernandes, G.W., 2001. Tadpole distribution within montane meadow streams at the Serra do Cipó, southeastern Brazil: ecological or phylogenetic constraints? J. Trop. Ecol. 17, 683-693.

Glasser, J.W., 1989. Temporal patterns in species' abundances that imply balance between competition and predation. Am. Nat. 134, 120-127.

Gotelli, N.J., 2000. Null model analysis of species co-occurrence patterns. Ecology 81, 2606-2621.

Gotelli, N.J., Entsminger, G.L., 2003. Swap algorithms in null model analysis. Ecology $84,532-535$.

Gotelli, N.J., Entsminger, G.L., 2007. EcoSim: Null Models Software for Ecology (version 7), seventh ed. Acquired Intelligence Inc. and Kesay-Bear, Jericho. Available at: http://garyentsminger.com/ecosim.htm.

Gotelli, N.J., Graves, G.R., 1996. Null Models in Ecology. Smithsonian Institution Press, Washington, D.C

Gotelli, N.J., McCabe, D.J., 2002. Species co-occurrence: a meta-analysis of J.M. Diamond's assembly rules model. Ecology 83, 2091-2096.

Gotelli, N.J., Rohde, K.R., 2002. Co-occurrence of ectoparasites of marine fishes: a null model analysis. Ecol. Lett. 5, 100-111.

Heino, J., 2009. Species co-occurrence, nestedness and guild-environment relationships in stream macroinvertebrates. Freshw. Biol. 54, 1947-1959.

Heyer, W.R., McDiarmid, R.W., Weigmann, D.L., 1975. Tadpoles, predation and pond habitats in the tropics. Biotropica 7, 100-111.

Hofer, U., Bersier, L., Borcard, D., 1999. Spatial organization of a herpetofauna on an elevational gradient revealed by null model tests. Ecology 80, 976-988.

Hofer, U., Bersier, L., Borcard, D., 2004. Relating niche and spatial overlap at the community level. Oikos 106, 366-376.

Instituto Brasileiro de Geografia e Estatística - IBGE, 2004. Mapa de Biomas do Brasil: primeira aproximação. Available at: http://www.ibge.gov.br/home/ presidencia/noticias/noticia_visualiza.php?id_noticia=169 Rio de Janeiro.

Jenkins, D.G., 2006. In search of quorum effects in metacommunity structure: species co-occurrence analysis. Ecology 87, 1523-1531.

Kelt, D.A., Brown, J.H., 1999. Community structure and assembly rules: confronting conceptual and statistical issues with data on desert rodents. In: Weiher, E. Keddy, P. (Eds.), Ecological Assembly Rules: Perspectives, Advances, Retreat. Cambridge University Press, Cambridge, pp. 75-107.

Krüger, R.F., Carvalho, C.J.B., Ribeiro, P.B., 2010. Assembly rules in muscid fly assemblages in the grasslands biome of southern Brazil. Neotrop. Entomol. 39, 345-353.

Lawler, S.P., Morin, P.J., 1993. Temporal overlap, competition, and priority effects in larval anurans. Ecology 74, 174-182.

Luiselli, L., 2006. Resource partitioning and interspecific competition in snakes: the search for general geographical and guild patterns. Oikos 114, 193-211.

Luiselli, L., 2008. Resource partitioning in freshwater turtle communities: a null model meta-analysis of available data. Acta Oecol. 34, 80-88.

Maltez-Mouro, S., Maestre, F.T., Freitas, H., 2010. Co-occurrence patterns and abiotic stress in sand-dune communities: their relationship with spatial scale and the stress estimator. Acta Oecol. 36, 80-84.

Maluf, J.R.T., 2000. Nova classificação climática do Estado do Rio Grande do Sul. Rev. Bras. Agromet. 8, 141-150.

McDiarmid, R.W., Altig, R., 1999. Tadpoles: the Biology of Anuran Larvae. The University of Chicago Press, Chicago/London.

Medeiros, P.R., Grempel, R.G., Souza, A.T., Ilarri, M.I., Rosa, R.S., 2010. Non-random reef use by fishes at two dominant zones in a tropical, algal-dominated coastal reef. Environ. Biol. Fish. 87, 237-246.

Morin, P.J., 1983. Predation, competition, and the composition of larval anuran guilds. Ecol. Monogr. 53, 119-138.

Morin, P.J., 1987. Predation, breeding asynchrony, and the outcome of competition among treefrog tadpoles. Ecology 68, 675-683. 
Morin, P.J., Johnson, E.A., 1988. Experimental studies of asymmetric competition among anurans. Oikos 53, 398-407.

Parris, M.J., Semlitsch, R.D., 1998. Asymmetric competition in larval amphibian communities: conservation implications for the northern crawfish frog, Rana areolata circulosa. Oecologia 116, 219-226.

Pitzalis, M., Luiselli, L., Bologna, M.A., 2010. Co-occurrence analyses show that nonrandom community structure is disrupted by fire in two groups of soil arthropods (Isopoda Oniscidea and Collmebola). Acta Oecol. 36, 100-106.

Prado, C.P.A., Uetanabaro, M., Haddad, C.F.B., 2005. Breeding activity patterns, reproductive modes, and habitat use by anurans (Amphibia) in a seasonal environment in the Pantanal, Brazil. Amphibia-Reptilia 26, 211-221.

Resetaritis, W.J., Wilbur, H.R., 1991. Calling site choice by Hyla chrysoscelis: effect of predators, competitors and ovoposition sites. Ecology 72, 778-786.

Richter-Boix, A., Llorente, G.A., 2007. A comparative study of predator-induced phenotype in tadpoles across a pond permanence gradient. Hydrobiologia 583, 43-56.

Richter-Boix, A., Llorente, G.A., Montori, A., 2007a. Hierarchical competition in pondbreeding anuran larvae in a Mediterranean area. Amphibia-Reptilia 28, 247-261.

Richter-Boix, A., Llorente, G.A., Montori, A., 2007b. Structure and dynamics of an amphibian metacommunity in two regions. J. Anim. Ecol. 76, 607-618.

Rossa-Feres, D.C., Jim, J., 1996. Distribuição espacial em comunidades de girinos na região de Botucatu, São Paulo. Rev. Bras. Biol. 56, 309-316.

Ryan, T.J., Winne, C.T., 2001. Effects of hydroperiod on metamorphosis in Rana sphenocephala. Am. Midl. Nat. 145, 46-53.

Sanchez, L.C., Peltzer, P.M., Lajmanovich, R.C., 2009. Structure of wetland-breeding anuran assemblages from the southern section of the Paraná river, Argentina. Herpetol. J. 19, 173-184.
Sanderson, J.G., 2004. Null model analysis of communities on gradients. J. Biogeogr. 31, 879-893.

Sfenthourakis, S., Tzanatos, E., Giokas, S., 2005. Species co-occurrence: the case of congeneric species and a causal approach to patterns of species association. Glob. Ecol. Biogeogr. 15, 39-49.

Simberloff, D., Dayan, T., 1991. The guild concept and the structure of ecological communities. Annu. Rev. Ecol. Syst. 22, 115-143.

Snodgrass, J.W., Komoroski, M.J., Bryan, A.L., Burger, J., 2000. Relationships among isolated wetland size, hydroperiod, and amphibian species richness: implications for wetland regulations. Conserv. Biol. 14, 414-419.

Stone, L., Roberts, A., 1990. The checkerboard score and species distributions. Oecologia 85, 74-79.

Taylor, C.M., Gotelli, N.J., 1994. The macroecology of Cyprinella: correlates of phylogeny, body size, and geographic range. Am. Nat. 144, 549-569.

Tilman, D., Mattson, M., Langer, S., 1981. Competition and nutrient kinetics along a temperature gradient: an experimental test of a mechanistic approach to niche theory. Limnol. Oceanogr. 26, 1020-1033.

Toft, C.A., 1985. Resource partitioning in amphibians and reptiles. Copeia 1985, $1-21$

Welborn, G.A., Skelly, D.K., Werner, E.E., 1996. Mechanisms creating community structure across a freshwater habitat gradient. Annu. Rev. Ecol. Syst. 27, 337-363.

Wilbur, H.M., 1987. Regulation of structure in complex systems: experimental temporary pond communities. Ecology 68, 1437-1452.

Wild, E.R., 1996. Natural history and resource use of four Amazonian tadpole assemblages. Occas. Pap. Mus. Nat. Hist. Univ. Kansas 176, 1-59. 